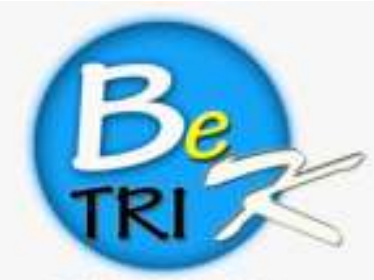

ISSN : $2339-1871$

\section{JURNAL ILMIAHBETRIK Besemah Teknologi Informasi dan Komputer}

Editor Office : LPPM Sekolah Tinggi Teknologi Pagar Alam, Jn. Masik Siagim No. 75 Simpang Mbacang, Pagar Alam, SUM-SEL, Indonesia Phone : +62 852-7901-1390.

Email : betrik@lppmsttpagaralam.ac.id |admin.jurnal@lppmsttpagaralam.ac.id Website : https://ejournal.lppmstipagaralam.ac.id/index.php/betrik/index

\title{
IMPLEMENTASI MODEL ADDIE PADA EDUCATION GAME PEMBELAJARAN BAHASA INGGRIS (STUDI KASUS PADA SMP NEGERI 8 PAGARALAM )
}

\author{
Siti Aminah \\ Dosen Sekolah Tinggi Teknologi Pagar Alam \\ Jalan Masik Siagim No. 75 Simpang Mbacang Kec.Dempo Tengah Pagar Alam \\ Email : gosupeta@gmail.com
}

\begin{abstract}
ABSTRAK : Tujuan dari pemelitian ini adalah menerapkan model ADDIE pada multimedia pembelajaran yang berbentuk game. Berlatar belakang dari usaha untuk meningkatkan daya saing dan keunggulan kompetitif dari semua sektor, menuntut manusia untuk mempunyai kemampuan yang berkualitas, baik dari sumber daya manusia (SDM), ilmu pengetahuan dan teknologi agar manusia mampu bertahan dalam perkembangan zaman yang semakin canggih. Salah satu sarana yang harus dikuasai dalam menghadapi era globalisasi tersebut adalah kemampuan berkomunikasi dengan Bahasa Inggris, sehingga Bahasa Inggris sangat ditekankan penguasaannya di Indonesia. Penelitian dilakukan dengan merancang serta membangun education game multimedia pembelajaran Bahasa Inggris pada SMP Negeri 8 Pagaralam. Dalam penelitian ini, model yang diimplementasikan adalah ADDIE, dengan melalui lima tahapan, yaitu analisis, desain, penembangan, implementasi dan evaluasi. Pada SMPN 8 Pagar Alam, penelitian ini juga digunakan untuk mengembangkan dan mengevaluasi perangkat lunak multimedia pembelajaran Bahasa Inggris untuk siswa Sekolah Menengah Pertama. Aplikasi Education game diharapkan dapat membantu guru memberikan materi kepada siswa dengan cara belajar sambil bermain untuk meningkatkan belajar siswa dalam pelajaran Bahasa Inggris. Aplikasi ini dibangun dengan konsep multimedia yang ini sangat efektif dan dapat digunakan sebagai alat bantu yang berisi materi dan soal latihan Bahasa Inggris untuk siswa didalam pembelajaran Bahasa Inggris.
\end{abstract}

Kata Kunci : Multimedia, Education game, ADDIE.

ABSTRACT: The purpose of this research is to apply the ADDIE model to learning multimedia in the form of games. The background of efforts to improve competitiveness and competitive advantage of all sectors requires people to have quality capabilities, both from human resources (HR), science and technology so that humans can survive in the development of increasingly sophisticated times. One of the tools that must be mastered in facing the era of globalization is the ability to communicate in English, so that English is very emphasized in Indonesia. The research was conducted by designing and building education on multimedia games for learning English at SMPN 8 Pagar Alam. In this study, the model implemented is ADDIE, through five stages, namely analysis, design, development, implementation and evaluation. At SMPN 8 Pagar Alam, this study was also used to develop and evaluate multimedia learning English language software for junior high school students. Education game applications are expected to help teachers provide material to students by learning while playing to improve student learning in English lessons. This application is built with a multimedia concept that is very effective and can 
be used as a tool that contains material and English practice questions for students in learning English.

Keyword : Multimedia, Education Game, ADDIE.

\section{PENDAHULUAN}

Pendidikan memiliki peran yang sangat penting dimasa anak-anak, karena perkembangan kepribadian, sikap mental dan intelektual dibentuk pada usia sekarang. Masa anak-anak merupakan masa yang tepat untuk memulai memberikan berbagai stimulus agar siswa dapat berkembang secara optimal. Pendidikan berasal dari kata didik, atau mendidik yang berarti memelihara dan membentuk latihan. Pendidikan adalah sebuah proses pembelajaran yang didapat oleh setiap manusia, dalam hal ini adalah peserta didik, tujuannya adalah untuk membuat siswa itu paham, mengerti serta mampu berpikir lebih kritis. Pendidikan dapat dirumuskan sebagai tuntunan pertumbuhan manusia sejak lahir hingga tercapai kedewasaan jasmani dan rohani, dalam interaksi alam dan lingkungan masyarakatnya.

Menurut (Arizal, 2011), kemajuan dibidang teknologi dan persaingan yang semakin ketat, agar dapat menguasai Bahasa Inggris yang merupakan bahasa internasional. Oleh sebab itu, pendidikan Bahasa Inggris perlu dikenalkan dan dipelajari. Karena Bahasa Inggris bukan merupakan bahasa mereka, sehingga mereka tidak terbiasa mendengar atau mengucapkan pelafalan dalam Bahasa Inggris. Penulis memilih siswa SMP sebagai target user karena mempertimbangkan kesulitan proses pembelajaran secara teoritis pada siswa mengingat siswa lebih suka bermain. Dengan adanya education game diharapkan dapat mengatasi masalah tersebut. Masuknya game dalam proses belajar, melahirkan suasana yang menyenangkan karena siswa tersebut dapat mengendalikan kecepatan belajar sesuai dengan kemampuan. Lalu dengan adanya gambar dan suara yang muncul membuat siswa tidak merasa bosan, sebaliknya akan menumbuhkan rasa ingin tahu para siswa.

Menurut teori education game adalah media pembelajaran yang membuat siswa bermain sambil belajar, dimana siswa tidak merasa terbebani dalam menguassai materi, karena mereka merasa sedang bermain-main dengan game yang merupakan permainan yang mereka sukai sehari-hari, sehingga materi dapat terserap dengan kemauan siswa sendiri. Siswa justru termotivasi untuk belajar agar dapat mengerjakan permainan dengan baik.

Berdasarkan penelitian (Dony, 2013) Aplikasi Game Geografi Berbasis Multimedia Interaktif (Studi Kasus Siswa Kelas IX SMPN 1 Rao). Penelitian ini bertujuan untuk menunjang pembelajaran terhadap siswa, terutama yang berhubungan pada mata pelajaran hafalan yaitu geografi. Selama ini media pembelajaran yang digunakan bersifat monoton dan guru mengajar menggunakan metode konvensional, sehingga proses pembelajaran yang tidak efektif ini dapat ditanggulangi dengan menggunakan media pembelajaran interaktif. Game edukasi ini digunakan sebagai salah satu media 
pembelajaran yang memiliki pola pembelajaran learning by doing.

Berdasarkan penelitian (Rohwati, 2012) Penggunaan Education Game Untuk Meningkatkan Hasil Belajar IPA Biologi Konsep Klasifikasi Mahluk Hidup Tujuan penelitian ini untuk meningkatkan hasil belajar IPA Biologi tentang klasifikasi makhluk hidup bagi siswa kelas VII B SMP N 1 Wonosobo yang dilaksanakan pada semester 1 tahun 2009/2010. Pada siklus I diketahui hasil belajar meningkat tajam dari yakni dari 55,03 menjadi 81,71. Pada akhir siklus II hasil belajar meningkat menjadi 87,57. Jadi pembelajaran menggunakan education game dapat meningkatkan hasil belajar, keaktifan siswa dalam pembelajaran, penguasaan bahasa serta penggunaan ICT dalam pembelajaran

Sekolah Menengah Pertama Negeri 8 Pagaralam merupakan salah satu Sekolah yang masuk dalam daftar Sekolah Model yang ada di Kota Pagaralam yang berdiri pada tahun 2003. SMP Negeri 8 dilengkapi dengan Teknologi pendukung seperti komputer, jaringan internet serta LCD Proyektor dan Lab Komputer, untuk mempermudah menerapkan aplikasi education game dengan memanfaatkan teknologi untuk pembelajaran agar dapat meningkatkan pemahaman siswa terhadap materi pelajaran Bahasa Inggris.

Dari uraian diatas, penulis membuat suatu aplikasi yang nantinya akan membantu dalam proses belajar mengajar, terutama dalam pembelajaran Bahasa Inggris di SMP Negeri 8 Pagaralam. Perancangan aplikasi education game ini dibuat dengan berbasis Multimedia agar dapat mempermudah proses belajar siswa dengan konsep belajar sambil bermain. Berdasarkan uraian diatas maka penulis membuat aplikasi dengan judul " Implementasi Model Addie Pada Education Game Pembelajaran Bahasa Inggris (Studi Kasus Pada Smp Negeri 8 Pagaralam )”.

\section{METODE PENELITIAN}

\subsection{Pengertian Aplikasi}

Menurut (jogiyanto, 2005) aplikasi adalah penggunaan dalam suatu komputer, intruksi (instruction) atau pernyataan (statement) yang disusun sedemikian rupa sehingga komputer dapat memproses input menjadi output. Menurut kamus besar Bahasa Indonesia (2005), “Aplikasi adalah penerapan dari rancang sistem untuk mengolah data yang menggunkan aturan atau ketentuan bahasa pemrograman tertentu".

Menurut Jogiyanto (2004) Aplikasi merupakan program yang berisikan perintahperintah untuk melakukan pengolahan data. Dan aplikasi secara umum adalah suatu proses dari cara manual yang ditransformasikan ke komputer dengan membuat sistem atau program agar data diolah lebih berdaya guna secara optimal.

\subsection{Pengertian Education Game}

Menurut (Ghea, 2012) Education game adalah salah satu jenis media yang digunakan untuk memberikan pengajaran, menambah pengetahuan penggunanya melalui suatu media unik dan menarik. Jenis ini biasanya ditujukan untuk anak-anak, maka permainan warna sangat diperlukan disini bukan tingkat kesulitan yang dipentingkan. 
Game adalah kata Bahasa Inggris yang berarti permainan atau pertandingan, atau bisa diartikan sebagai aktifitas terstruktur yang biasanya dilakukan untuk bersenangsenang. Menurut Anggra (Zulfadli Fahrul Rozi, 2010) game atau permainan adalah sesuatu yang dapat dimainkan dengan aturan tertentu sehingga ada yang menang dan ada yang kalah, biasanya dalam konteks tidak serius. Macam-macam game, antara lain:

a.Aksi

Game ini macam game yang paling populer. Game jenis ini membutuhkan kemampuan refleks pemain.

b. Aksi petualangan

Game ini memadukan game play aksi petualangan. Contohnya pemain diajak untuk menyelusuri gua bawah tanah sambil mengalahkan musuh atau menyeberangi sungai.

c.Simulasi, Konstruksi dan Manajemen

Pemain dalam game ini diberi keleluasaan untuk membangun dan suatu proyek tertentu dengan bahan baku yang terbatas.

d. Olahraga

Geme ini membawa olahraga ke dalam sebuah komputer atau konsol. Biasanya gameplay dibuat semirip mungkin dengan kondisi olahraga yang sebenarnya.

e.Puzzle

Geme puzzle menyajikan teka-teki, menyamakan warna bola, perhitungan matematika, menyusun balok, atau mengenal huruf dan gambar.
Word game sering dirancang untuk menguji kemampuan dengan bahasa atau untuk mengeksplorasi sifatsifatnya. Word game umumnya digunakan sebagai sumber hiburan, tetapi telah dibuktikan untuk melayani suatu tujuan pendidikan juga

Jadi, education game adalah permainan yang dirancang khusus untuk mengajarkan siswa dalam suatu pelajaran tertentu dengan konsep bermain sambil belajar.

\subsection{Pengertian Multimedia}

Menurut (Suyanto, 2005) Multimedia merupakan kombinasi dari komputer dan video. Rosch (1996) atau multimedia secara umum merupakan kombinasi tiga elemen,yaitu suara gambar dan teks. McCormick (1996). atau multimedia adalah kombinasi dari paling sedikit dua media input atau output dari data, media ini dapat audio, animasi, video, teks, grafik dan gambar (Turban dkk, 2002).

Definisi yang lain dari multimedia, yaitu dengan menempatkan dalam konteks, seperti yang dilakukan oleh Hofstetter (2001) multimedia adalah pemanfaatan komputer untuk membuat dan menggabungkan teks, grafik, audio, gambar bergerak (video dan animasi) dengan menggabungkan link dan tool yang memungkinkan pemakai melakukan navigasi, berinteraksi, berkreasi dan berkomunikasi.

Kegunaan multimedia antara lain adalah:

1. Pada bidang pemasaran, multimedia digunakan untuk persentasi atau mempromosikan produk atau gagasan yang

\section{f.Permainan Kata}


ingin dipasarkan dalam bentuk yang lebih jelas dan memikat.

2. Pada bidang pendidikan, multimedia digunakan untuk memvisualisasikan pelajaran-pelajaran yang sulit diterangkan dengan cara konvensional

3. Pada bidang hiburan multimedia digunakan dalam program-program permainan untuk membentuk suasana yang lebih menarik dan interaktif.

4. Pada bidang perfilman, multimedia digunakan untuk pembuatan film animasi, pembuatan film kartun sehingga film tersebut menjadi efektif dan efisien

5. Pada bidang kesehatan, multimedia dapat mendukung pelayanan dan fasilitas sistem kesehatan yang mempromosikan jasa dan penelitian lewat situs Web Sistem Kesehatan.

\subsection{Metode Pengembangan Sistem}

Model pendekatan ini umumnya merekomendasikan urutan aktivitas yang meliputi analisis,desain, development, implementasi, dan evaluasi ( ADDIE). Gagne, Wager, Golas dan Keller (2005) memperluas langkahADDIE ke dalam petunjuk prosedural yang lebih detail menjadi :

\section{Analisis}

Kegiatan utama yang dilakukan pada tahap ini adalah menganalisis latar belakang atau perlunya pengembangan media pembelajaran dan menganalisis kelayakan serta syarat-syarat pengembangan media pembelajaran. Setelah menganalisis perlunya pengembangan dilakukan, peneliti juga perlu melakukan analisis pada kelayakan dan syarat-syarat pengembangan media pembelajaran. Analisis ini dilakukan untuk mengetahui kelayakan apabila media pembelajaran tersebut digunakan.

\section{Desain}

Tahap ini merupakan tahap perancangan dari media pembelajaran. Kegiatan ini merupakan tahapan sistematik yang dimulai dari menetapkan tujuan media pembelajaran,merancang materi atau kegiatan belajar mengajar,dan evaluasi dari pembelajaran. Rancangan ini bersifat konseptual untuk mendasari proses pengembangan berikutnya.

\section{Development}

Tahap development dalam model ADDIE berisi kegiatan realisasi rancangan produk. Pada tahap sebelumnya rancangan yang telah disusun direalisasikan menjadi produk yang siap diimplementasikan.

\section{Implementasi}

Rancangan dan produk yang telah selesai direalisasi diimplementasikan pada situasi dan kelas yang nyata. Dari implementasi yang telah dilakukan akan didapatkan evaluasi awal untuk memberi umpan balik pada penerapan media pembelajaran tersebut.

\section{Evaluasi}

Tahap evaluasi dilakukan dalam dua tahap, yaitu formatif dan sumatif. Evaluation formatif dilaksanakan ketika setelah tatap muka sedangkan sumatif 
dilakukan setelah semua kegiatan pembelajaran berakhir. Evaluasi sumatif dilakukan untuk mengukur kompetensi akhir dari mata pelajaran pada pengembangan media pembelajaran. Hasil evaluasi digunakan untuk memberi umpan balik kepada pihak pengguna media pembelajaran.

\subsection{Sistem Yang Berjalan}

Sebelum melakukan perancangan terhadap suatu multimedia pembelajaran, terlebih dahulu akan dianalisa sistem pembelajaran yang sedang berjalan dalam penyampaian materi mata pelajaran Bahasa Inggris pada siswa kelas VII di SMP Negeri 8 Pagaralam. Hal ini dilakukan untuk mengetahui dan mempelajari kelemahan sistem pembelajaran tersebut dan masalah yang dihadapi, dimana saat ini dalam penyampaian materi Bahasa Inggris masih menggunakan media konvensional, yaitu menggunakan papan tulis dan buku sebagai alat bantu ajar dalam penyampaian materi Bahasa Inggris. Maka sistem pembelajaran dapat di lihat dalam gambar berikut

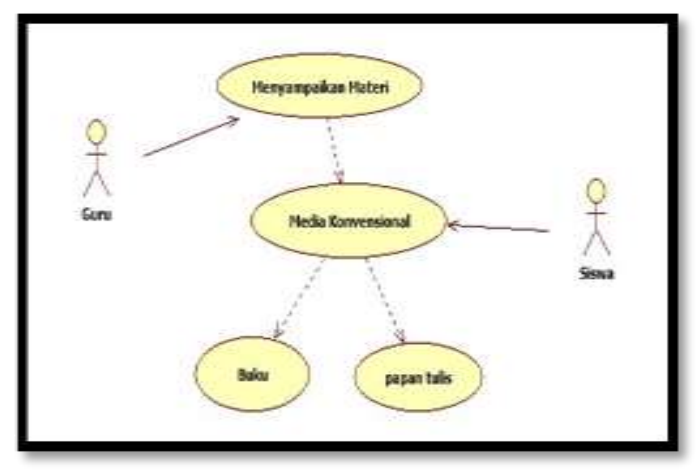

Gambar 1. Sistem Yang Berjalan

\subsection{Flowchart}

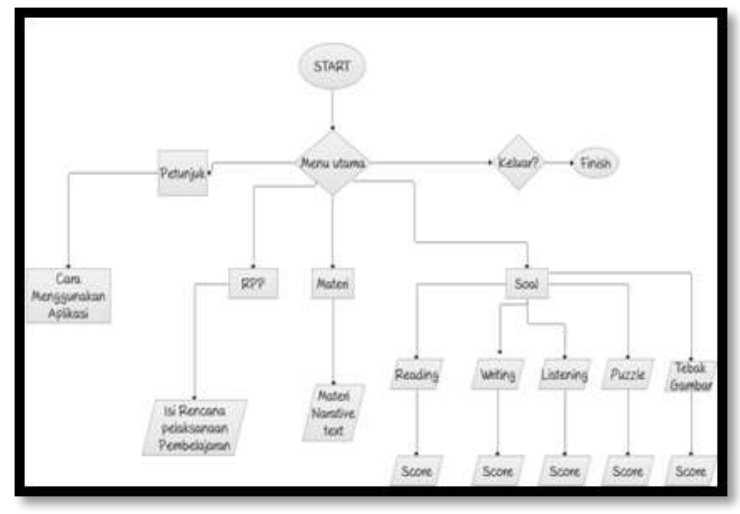

Gambar 2. Flowchart Sistem Yang Diusulkan

Berikut adalah tampilan flowchart sistem yang diusulkan yang dapat dilihat pada gambar 3.3 ketika kita mulai aplikasi pada menu utama terdapat 5 sub menu pilihan yaitu menu petunjuk, RPP, materi, soal dan keluar. Pada menu petunjuk berisi tentang cara mengunakan aplikasi, pada menu RPP berisikan materi tentang rencana pelaksanaan pembelajaran pada SMP NEGERI 8 Pagaralam. Dan pada menu materi berisikan materi tentang narative text untuk menjawab soal yang berupa reading, writing, dan listening. Didalam menu soal terdapat 5 sub menu pilihan untuk menjawab soal dalam bentuk reading, writing, listening, puzzle dan tebak gambar yang menghasilkan skor. Pada menu keluar untuk mengakhiri aplikasi yang dijalankan.

\subsection{Rancangan Halaman utama}

Berdasarkan Gambar 3 pada saat program pertama kali dijalankan maka user dihadapkan pada tampilan utama aplikasi. 


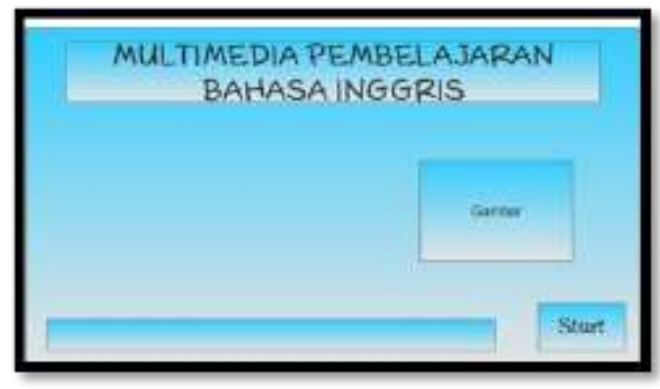

Gambar 3. Tampilan awal

\subsection{Tampilan Menu Pilihan}

Berdasarkan gambar dibawah tampilan menu utama yang terdiri dari 5 (Lima) pilihan menu, yaitu menu petunjuk, menu RPP, menu materi, menu soal dan menu keluar.

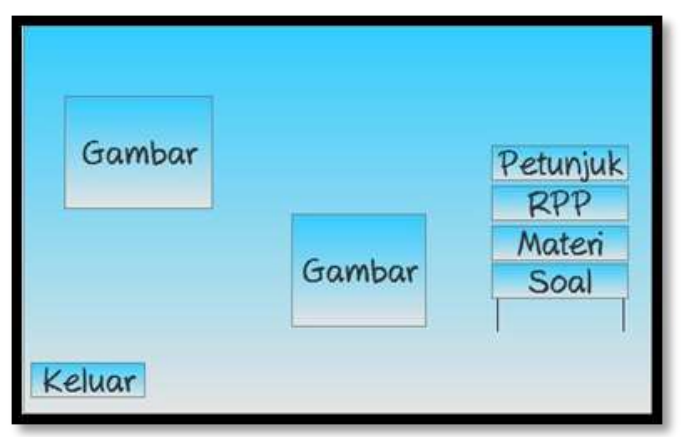

Gambar 4. Tampilan menu pilihan

\subsection{Tampilan Menu Petunjuk}

Pada tampilan menu petunjuk gambar 5 berisikan cara mengunakan aplikasi.

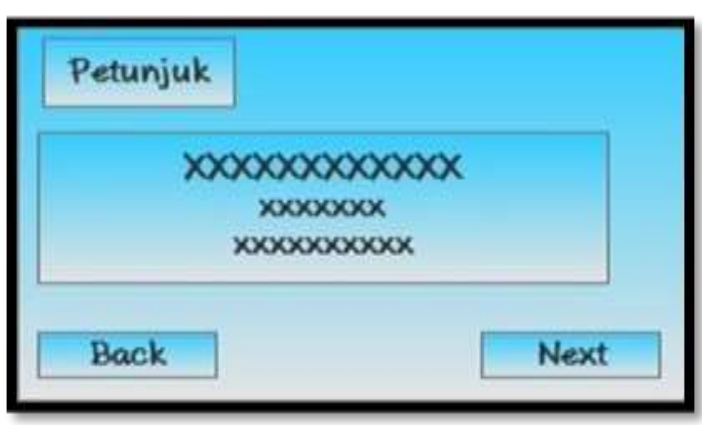

Gambar 5 Tampilan cara bermain

\section{HASIL DAN PEMBAHASAN}

\subsection{Hasil}

Hasil dari rancangan multimedia pembelajaran yang telah dibuat dapat dijalankan sesuai yang telah diharapkan. Program yang sudah dibuat diantaranya adalah pembelajaran Bahasa Inggris dengan menggunakan game puzzle, tebak gambar dan soal pilihan ganda materi untuk kelas VII SMP NEGERI 8 Pagaralam. Hasil dari perancangan multimedia pembelajaran ini memiliki beberapa keunggulan yaitu dengan program ini siswa dapat memahami materi dan mengerjakan soal dengan mudah. Dari segi tampilan multimedia lebih menarik dengan tampilan warna yang bagus dan banyak disukai banyak siswa karena dirancang secara interaktif. Tampilan pada menu utama di desain dan semenarik mungkin.

Aplikasi multimedia pembelajaran bahasa inggris di SMP Negeri 8 Pagaralam yang dihasilkan dapat dioperasikan berupa Aplikasi multimedia yaitu berisi halaman petunjuk, halaman RPP, halaman materi dan halaman soal. Siswa dapat mengoperasikan multimedia dengan memilih menu-menu tersebut dan terdapat materi pelajaran untuk kelas Tujuh SMP Negeri 8 Pagaralam. Seperti pada Menu Materi berisikan materi tentang reading, writing dan listening. Dalam menu soal terdapat 5 pilihan bentuk soal yaitu reading, writing, listening, puzzle, dan tebak gambar.

\subsection{Perangkat kebutuhan sistem}

Untuk dapat menjalankan Aplikasi Pembelajaran Bahasa Inggris Berbasis 
Multimedia ini maka membutukan perangkat laptop atau komputer sebagi berikut:

1.Perangkat keras (Hardware) yang terdiri dari
a. Processor intel
b. Hardisk $500 \mathrm{~GB}$
c. $R A M 2 \mathrm{~GB}$
d. Speaker

2. Perangkat Lunak (Software)

e. Windows 7

f. Macromedia Flash 8 / Adobe Flash Cs6

g. Adobe Photoshop Cs6

h. Axure RP Pro 7.0

i. StarUML

\subsection{Penyajian Rancang Bangun Aplikasi} Education Game Pembelajaran Bahasa Inggris Berbasis Multimedia Pada SMP NEGERI 8 Pagaralam

Hasil pembuatan rancang bangun aplikasi education game pembelajaran bahasa inggris berbasis multimedia pada SMP Negeri 8 Pagaralam dengan mengunakan struktur bahasa pemrograman adobe flash Cs6.

\subsection{Cara pengoperasian}

Langka pertama untuk menggunakan aplikasi ini, pastikan sudah terinstal macromedia flash 8/ Adobe flash Cs6 untuk menjalankanya.

\subsection{Pembahasan}

Berikut ini adalah pembahasan dari hasil uji coba atau testing education game pembelajaran Bahasa Inggris. Berikut ini adalah tampilan dari masing-masing menu yang ada pada game puzzle berbasis multimedia

\subsection{Penyajian Desain Menu Utama}

\subsubsection{Halaman Menu Utama}

Sebelum siswa akan memulai memainkan Aplikasi ini siswa akan dihadapkan dengan menu loading. Desain halaman utama dapat dilihat pada gambar dibawah ini.

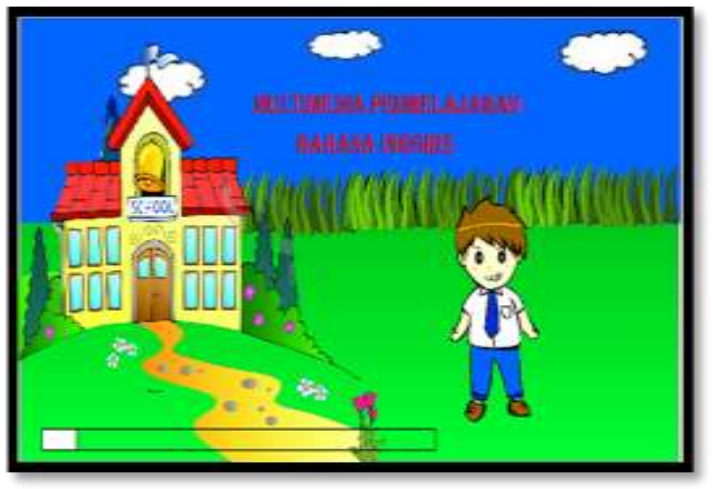

Gambar 6. Desain Menu Utama

\subsubsection{Halaman Menu Pilihan}

Tampilan pada saat siswa akan memulai dan ada beberapa menu pilihan yaitu, menu petunjuk, menu RPP, menu Materi, menu Soal dan keluar.

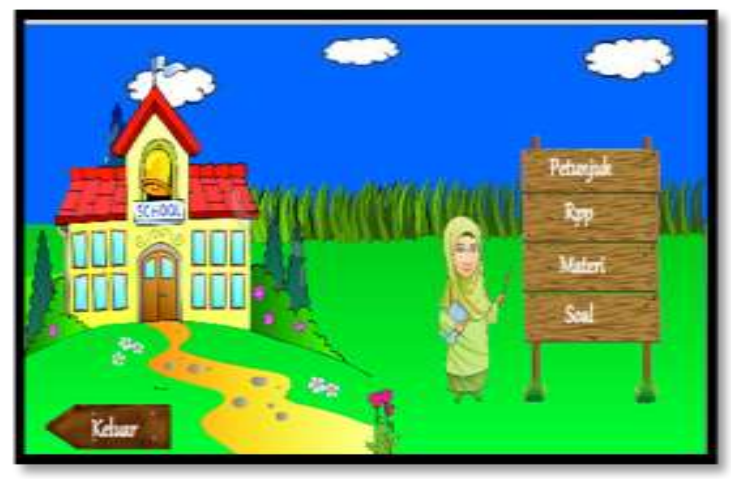

Gambar 7. menu pilihan

\subsubsection{Halaman Menu Petunjuk}

Pada halaman petunjuk di halaman utama game yang didapat pada 
tampilan ini adalah tentang cara bermain, dapat dilihat pada gambar dibawah ini.

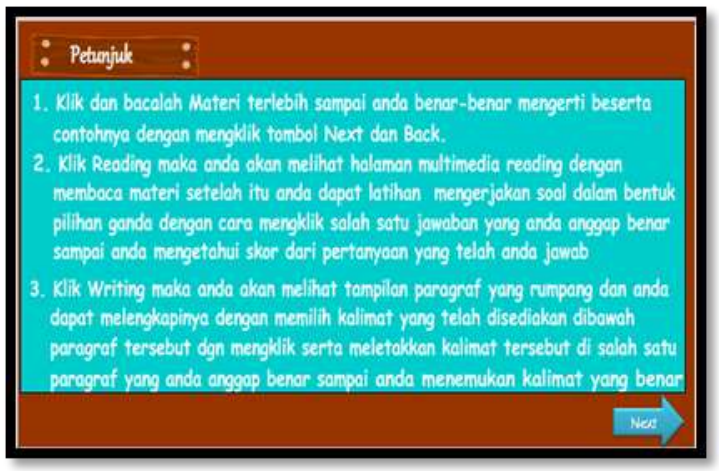

Gambar 8. menu petunjuk

\subsubsection{Halaman Menu RPP}

Didalam menu RPP terdapat rencana kegiatan pembelajaran yang di berikan kepada siswa. Dapat dilihat pada gambar dibawah ini.

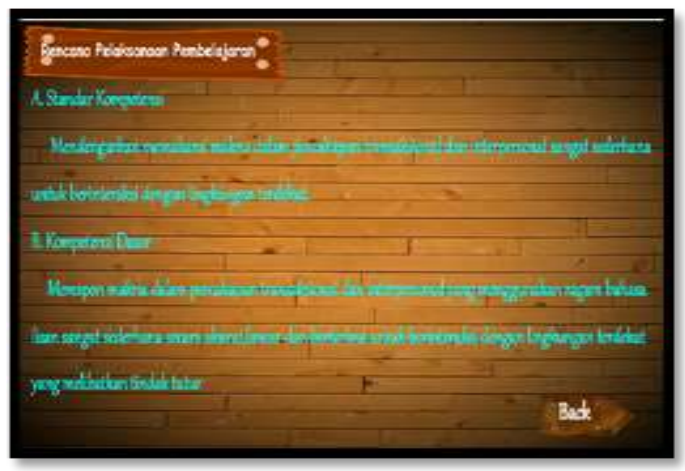

Gambar 9. menu RPP

\subsubsection{Halaman Menu Materi}

Halaman menu materi ini berisi tentang materi reading, writimg dan listening. Dapat dilihat pada gambar dibawah ini.

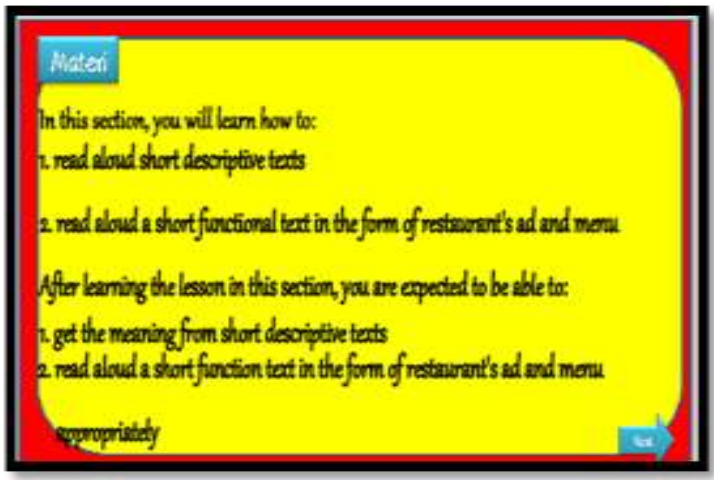

Gambar 10. menu Materi

\subsubsection{Halaman Menu Pilihan Soal}

Tampilan soal latihan ada beberapa pilihan ketika siswa akan memulai memainkannya, dapat dilihat pada gambar dibawah ini.

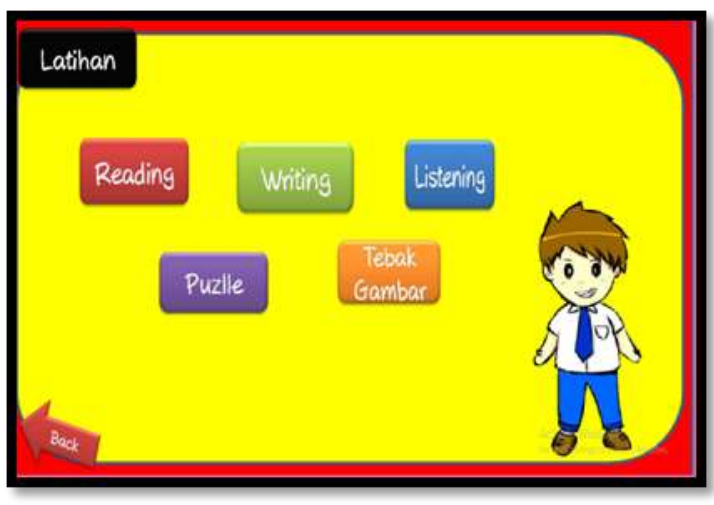

Gambar 11. Halaman Pilihan Soal

\subsubsection{Halaman Reading}

\section{Sebelum mengerjakan} soal reading harus mengisi nama, dapat dilihat gambar dibawah ini.

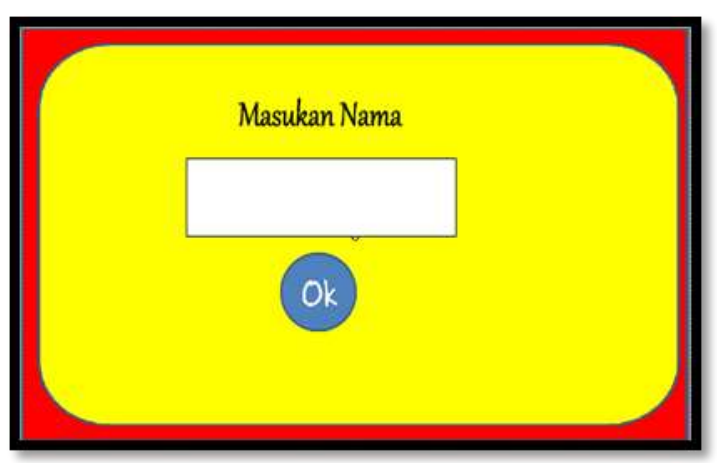

Gambar 12. Input Nama 
Pada tampilan menu soal Reading. Didalam menu soal yang berbentuk pilihan ganda.

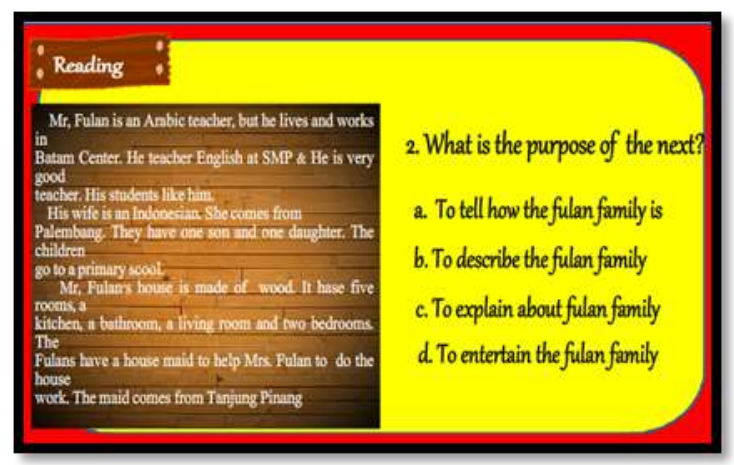

Gambar 13.Halaman Soal Reading

Setelah menjawab semua soal siswa dihadapkan pada halaman skor, hasil akhir dari soal reading.

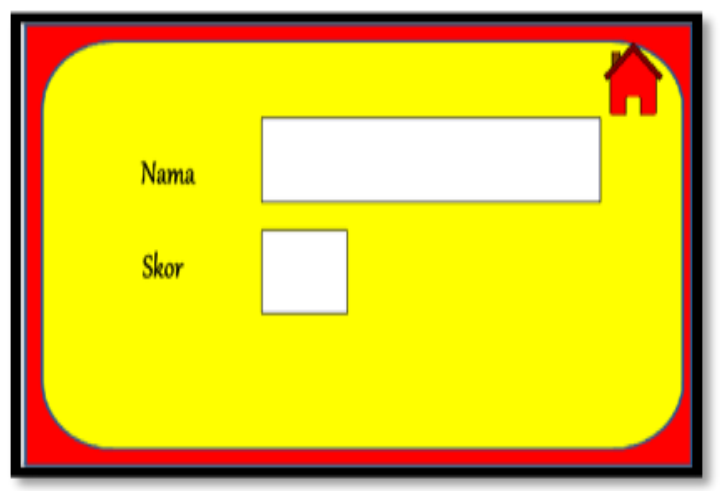

Gambar 14. Halaman Skor

\subsubsection{Halaman Writing}

Sebelum mengerjakan soal writing harus mengisi nama, dapat dilihat gambar dibawah ini.

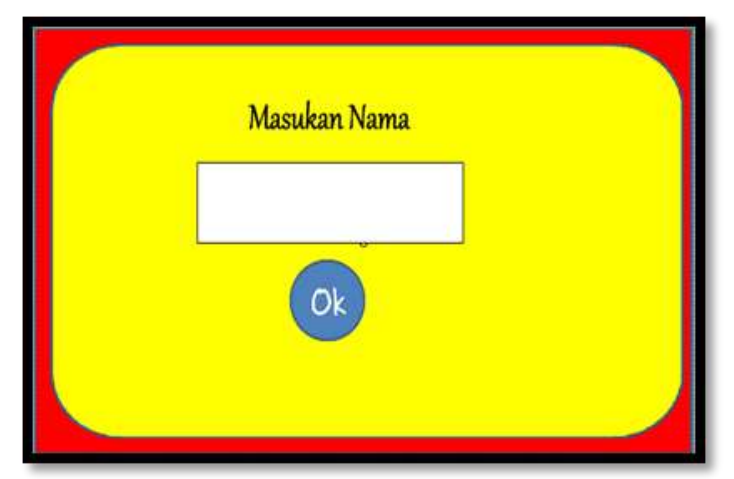

Gambar 15. input Nama
Tampilan menu soal writing

berisikan soal yang diketik untuk mengisi jawaban tersebut.

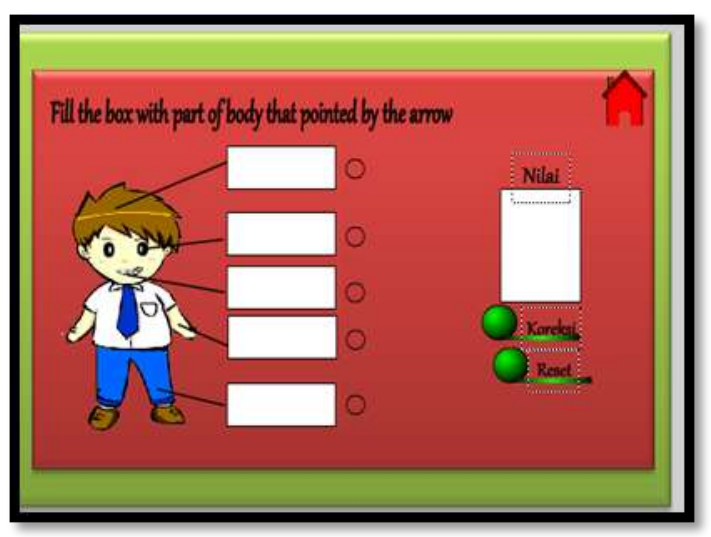

Gambar 16. Halaman soal Writing

\section{SIMPULAN}

Dengan adanya pembuatan multimedia pembelajaran Bahasa Inggris pada SMP Negeri 8 Pagaralam berbasis multimedia menggunakan adobe cs 6 , sangat mungkin diperoleh multimedia pembelajaran yang modern dan menarik. Dari penelitian yang dilakukan pada sistem pembelajaran SMP Negeri 8 Pagaralam maka penulis membuat kesimpulan sebagai berikut :

1. Penelitian ini menghasilkan multimedia pembelajaran Bahasa Inggris pada SMP Negeri 8 Pagar alam.

2. Multimedia Pembelajaran Bahasa Inggris dibuat untuk memudahkan siswa-siswi, dan guru untuk melakukan kegiatan belajar mengajar disekolah maupun di luar.

\section{DAFTAR RUJUKAN}


Anjaya, T. (2013). Pengembangan Media Pembelajaran Pneumatik Dan Hidrolik Berbasis Adobe Flash CS6 Program Studi Diploma 3 Teknik Otomatif

Fitriyah \& Busran (2015), Perancangan Permainan (Game) Edukasi Belajar Membaca Pada Anak Prasekolah Berbasis Smartphone Android. Teknik Informatika.

Fakultas Teknologi Industri Institut Teknologi Padang.

Ghea Putri Fatma Dewi (2012). Pengembangan Game Edukasi Pengenalan Nama Hewan Dalam Bahasa Inggris Sebagai Media Pembelajaran Siswa SD Berbasis Macromedia Flash. Prodi Pendidikan Teknik Informatika, Fakultas Teknik. Universitas Negeri Yogyakarta

Novaliandry Dony (2013). Aplikasi Game Geografi Berbasis Multimedia Interaktif (Studi Kasus Siswa Kelas IX SMPN 1 Rao)

Prof.Dr.Sugiyono (2016), Metode Penelitian Kombinasi Mixed Methods. Alfabeta, Bandung.

Radi Arizal (2011), Education Game Bahasa Inggris Untuk Anak-Anak Usia 4-12 Tahun. Universitas Bina Darma.

Raharjo Nathania (2013), Pembuatan Game Kecerdasan Verbal-Visual Untuk Siswa Tk-B. Teknik Informatika . Fakultas Teknik Universitas Surabaya. Rinaldo (2015), Perancangan dan Implementasi e-learning pada SMA Muhammadiyah
Jarai Berbasis Web. Teknik Informatika. Sekolah Tinggi Teknologi Pagaralam.

Rohwati.M (2012), Penggunaan Education Game Untuk Meningkatkan Hasil Belajar Ipa Biologi Konsep Klasifikasi Makhluk Hidup. Prodi Pendidikan IPA FMIPA UNNES Semarang. http://journal.unnes.ac.id/index.php/jpii

Rosa \& M.Shalahuddin (2014) ,Rekayasa Perangkat Lunak Terstruktur dan Berorientasi Objek. Informatika Bandung, Bandung.

Sukandi andi (2013) Education Game Pembelajaran Bahasa Inggris pada SMA PGRI Pagaralam. Teknik Informatika. Sekolah Tinggi Teknologi Pagaralam.

Sulviana Evi, dkk (2010) , Rancang Bangun Edugame Pembelajaran Kesehatan Gigi Untuk Anak-Anak Berbasis Unity $3 D$. Prodi Teknik Informatika, STMIK, Palembang.

Sutopo Hadi Ariesto (2003), Multimedia Interaktif dengan Flash. Ghala ilmu Suyanto.M (2005), Multimedia Alat untuk Meningkatkan Keunggulan Bersaing. Andi Yogyakarta. 